\title{
Membuat Website Sederhana
}

\author{
Muhammad Rio Prasetiawan dan Jefry Fredi \\ Mahasiswa Program Studi Teknik Komputer, \\ Jurusan Teknologi Informasi, Politeknik Negeri Samarinda
}

\begin{abstract}
Abstrak
Website saat ini berkembang dengan pesat pada berbagai bidang kehidupan manusia.Pada mulanya perkembangan website hanya bersifat pertukaran informasi yang statis artinya komunikasi yang terjadi antara penerima informasi dengan penyedia informasi hanya bersifat satu arah saja. Penerima hanya mendapatkan informasi dari penyedia informasi dan tidak dapat berinteraksi dengan penyedia tersebut. Biasanya sistem seperti ini disebut web statis.Seiring dengan berkembangnya industri-industri web, website tidak lagi bersifat statis. Penerima informasi tidak hanya mendapatkan informasi dari penyedia informasi, tetapi juga dapat berinteraksi dengan penyedia informasi dengan cara melakukan koneksi dengan basisdata. Sistem ini biasanya disebut web dinamik[1]. Pembuatan wensite itu sendiri menggunakan Bahasa pemrograman yang meliputi PHP, HMTL, CSS, dan MySQL. Bahasa pemrograman dapat dilakukan melalui pendidikan formal maupun informal seperti lembaga kursus atau pembelajaran secara online. Pembelajaran secara online memberikan berbagai keunggulan, diantaranya biaya yang lebih murah, waktu yang fleksibel dan setiap peserta dapat menyesuaikan dengan kemampuan dan perkembangan belajarnya[2].
\end{abstract}

Kata Kunci : Website, Bahasa Pemrograman

\section{Pendahuluan}

Website merupakan media untuk menanpilkan halaman. Website terbagi menjadi dua yaitu web statis dan web dinamis. Web statis adalah media untuk menampilkan halaman statis atau tetap, tetapi yang mengatur nya adalah web browser. Contoh teknologi yang berkaitan dengan web statis adalah Client Side seperti HTML, CSS. Sebelum kita melajutkanya lagi kita harus tau apa itu Website, HTML, dan CSS. Website adalah sebuah kumpulan halaman pada suatu domain di internet yang dibuat dengan tujuan tertentu dan saling berhubungan serta dapat diakses secara luas melalui halaman depan (home page) menggunakan sebuah browser menggunakan url website. HTML adalah singkatan dari Hypertext Markup Language yaitu bahasa pemrograman yang digunakan untuk membuat sebuah halaman web, yang kemudian dapat diakses untuk menampilkan berbagai informasi di dalam sebuah penjelajah web internet (browser). HTML merupakan sebuah bahasa yang bermula bahasa yang sebelumnya banyak dipakai di dunia percetakan dan penerbitan yang disebut Standard Generalized Markup Language (SGML). Oke pertama-tama saat mulai belajar CSS kamu tentu harus paham betul pengertiannya. Sebenarnya apa itu CSS? CSS adalah singkatan dari Cascading Style Sheets. Jika diterjemahkan ke bahasa Indonesia secara harfiah, CSS berarti "lembar penataan menurun". Namun secara konteks, Cascading Style Sheets adalah kumpulan perintah yang 
digunakan untuk menjelaskan tampilan sebuah halaman situs web dalam mark-up language. Mark-up language atau bahasa markah adalah bahasa pemrograman yang biasanya digunakan membuat website[3]. Tujuan dibuatnya laporan praktikum ini adalah untuk memenuhi tugas mata kuliah Pemrograman Web dan untuk berbagi ilmu kepada para pembaca dan dapat membuat halaman web dengan menggunakan kode HTML secara sederhana.

\section{Komponen Dan Alat Yang Dibutuhkan}

Sebelum membuat website kita harus mengenal dan mengetahui elemen atau hal-hal yang ada pada sebuah website. Sebab, bagaimanapun, setiap kita terkoneksi internet dan menggunakannya kita tidak akan terlepas dari sebuah aplikasi bernama "Web". Sebuah website tersusun dari komponen dan elemen dengan fungsinya masing-masing, lalu terkumpul dan saling berkaitan berikut ini adalah daftar elemen website yang umumnya tertampil. Untuk alat yang kita gunakan tidak banyak hanya Komputer/laptop, Koneksi internet HTML, CSS, Bootstrap, GitHub[4]. Saya tidak menjelaskan lagi apa itu html dan css karena sudah saya kasih tai di slide pertama jadi saya melaskan apa itu Bootstrap dan GifHub. Bootstrap adalah kerangka kerja CSS yang bersifat open source dan digunakan untuk kebutuhan pembuatan tampilan desain visual dari aplikasi web atau situs website. Kerangka kerja yang digunakan berbentuk template desain berbasis HTML dan CSS untuk kebutuhan pengembangan navigasi, tombol, tipografi, formulir, dan komponen antarmuka yang lainnya[5]. GitHub adalah aplikasi dengan basis website yang berfungsi untuk membantu penyimpanan repository. Namun tak hanya itu, dengan aplikasi ini Anda juga dapat melakukan kolaborasi dalam mengerjakan project tertentu agar dapat terus melakukan update secara rutin, termasuk melacak dan menyimpan perubahan-perubahan yang terjadi dalam project Anda tersebut[6].

\section{Komponen Yang Saya Pakai Untuk Website}

1. Title

Title adalah judul atau nama dari sebuah halaman web. Letaknya di titlebar browser.

Contoh :

\section{Small Project}

Small Project

jefryf7.github.io

2. Nama Domain

Nama domain adalah nama alias dari sebuah website.

Contoh : jefryf7.github.io 


\section{Alamat ULR}

Jika sebuah halaman web kita diibaratkan dengan rumah, maka URL ini adalah alamat lengkap rumah kita. Letaknya ada di addressbar browser.

Contoh :

(5) https://jefryf7.github.io/\#

\section{Link/Tautan}

Jika kita ibaratkan lagi bahwa sebuah halaman web adalah rumah, maka link atau tautan ini adalah pintu/gerbang/lorong yang menuju ke halaman lain baik itu yang masih satu web maupun halaman di web yang berbeda.

Contoh : https://jefryf7.github.io/\#Home

https://jefryf7.github.io/\#about

https://jefryf7.github.io/\#Galeri

https://jefryf7.github.io/\#contact

5. Header

Header adalah bagian atas dari sebuah website. Biasanya berisi nama situs, logo dan deskripsinya. Header berfungsi untuk menampilkan identitas utama dari sebuah situs. Contoh :

6. Konten/Isi

Konten atau isi sebuah situs berupa informasi dan artikel yang biasanya terletak dibagian tengah.

Contoh :

\section{About me}

Politeknik Negeri Samarinda Atau Di Singkat Polnes Adalah Sebuah Perguruan Tinggi Yang Terletak Di Kota Samarinda, Kalimantan Timur, Indonesia. Resmi Berdiri Pada Tanggal 3 Desember 1985
Polnes Memiliki Lokasi Kampus Di Jalan dr.Cipto Mangunkusumo, Kecamatan Samarinda Sebarang Dengan Luas Lahan 10 Hektar, Yang Di Lengkapi Gedung Direktorat, Ruang Kuliah, Ruang Serba Guna Dan Masih Banyak Yang Lagi.

7. Navbar

Navbar merupakan bagian website yang biasanya terletak di bagian paling atas dan bersifat melayang/fixed (Selalu terlihat walaupun di scroll).

Contoh :

\section{Home About Galeri Contact}


8. Form

From merupakan salah satu bentuk halaman web yang digunakan untuk menerima masukan dari pengguna.

Contoh :

\section{Contact Me}

Nama Lengkap
Email
Pesan

\section{Hasil}

1. Home

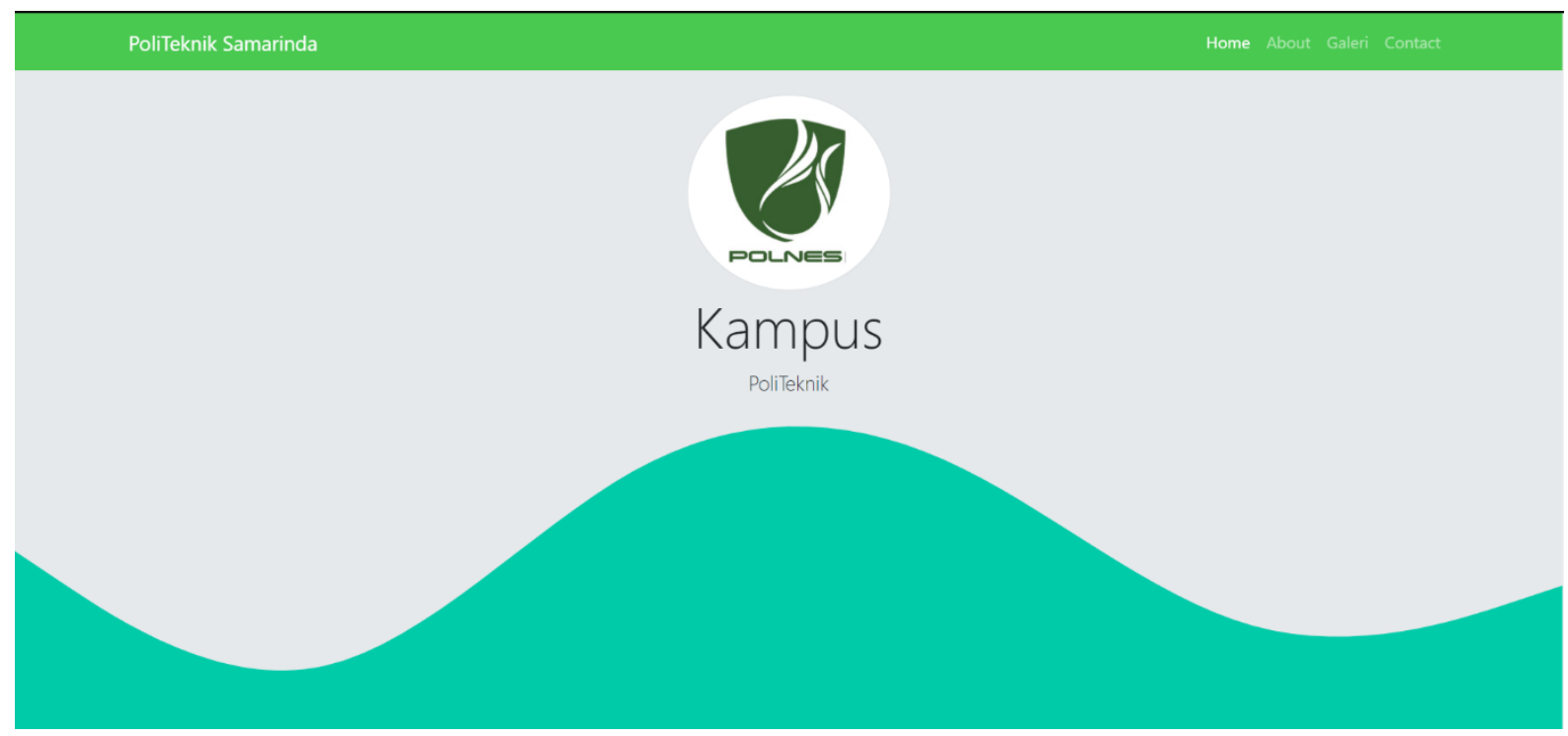




\section{About}

\section{About me}

Politeknik Negeri Samarinda Atau Di Singkat Polnes Adalah Sebuah Perguruan Tinggi Yang Terletak Di Kota Samarinda, Kalimantan Timur Indonesia. Resmi Berdiri Pada Tanggal 3 Desember 1985

Polnes Memiliki Lokasi Kampus Di Jalan dr.Cipto Manqunkusumo

Kecamatan Samarinda Sebarang Dengan Luas Lahan 10 Hektar, Yan

Di Lengkapi Gedung Direktorat, Ruang Kuliah, Ruang Serba Guna

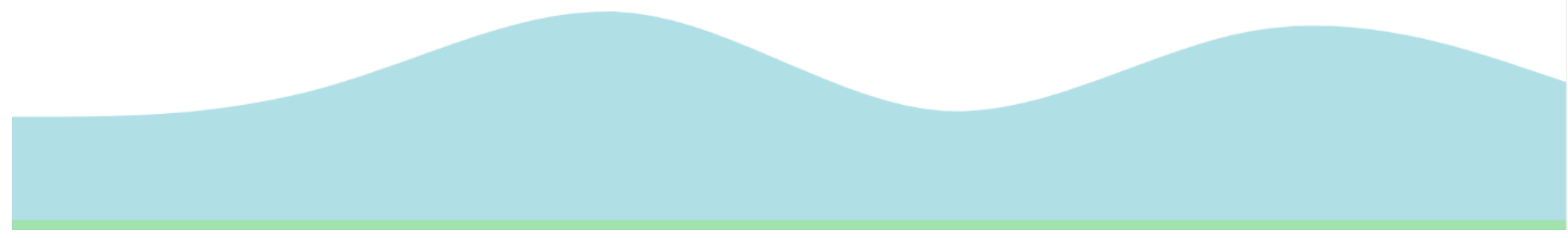

\section{Galeri}

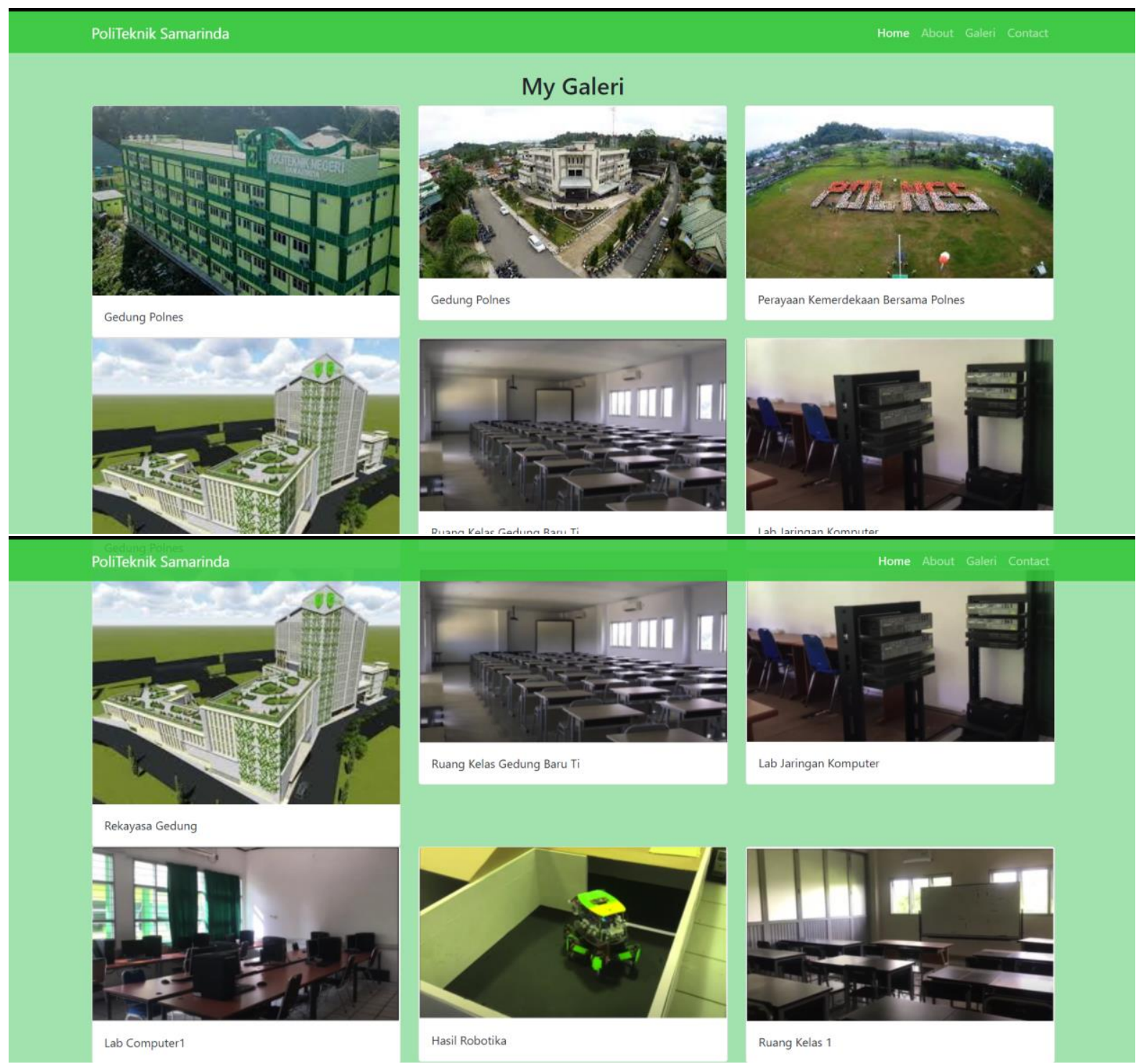


4. Contact

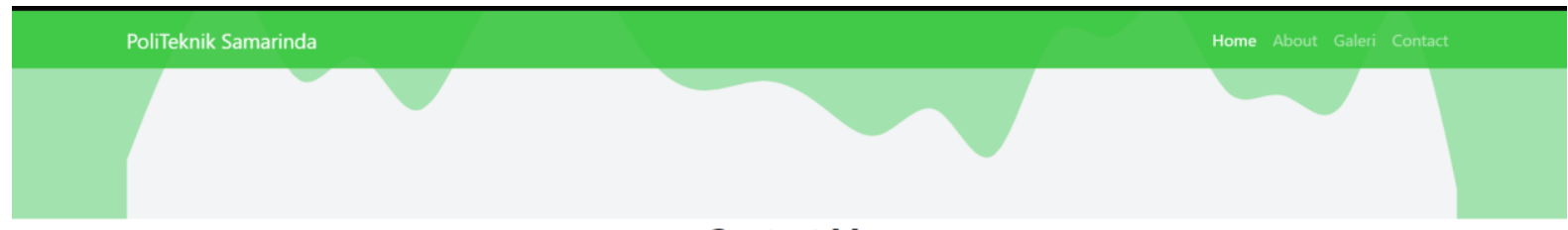

Contact Me

Nama Lengkap

Emai

Pesan

\section{Kesimpulan}

Perkembangan dunia informatika yang semakin canggih pada saat ini menawarkan kemudahan bagi setiap orang dalam membantu menyelesaikan segala kebutuhan dan pekerjaannya contohnya membuat web. Internet sebagai salah satu bukti nyata dengan adanya perkembangan ini. Maka dari itu para programmer berusaha untuk merancang beberapa pemrograman di internet. CSS dan HTML adalah komponen penting dalam pemrograman di internet karena bagus untuk para permula yang mau belajar membuat sebuah website[7]. 


\section{DAFTAR PUSTAKA}

[1] D. Marsita, "PEMBUATAN SITUS WEB ALMAMATER PERGURUAN TINGGI MENGGUNAKAN PHP DAN MySQL," Univ. Diponegoro, 2011.

[2] N. G. A. P. Harry Saptarini, R. A. Hidayat, and P. I. Ciptayani, "Ajarincode : Aplikasi Pembelajaran Bahasa Pemrograman Berbasis Web," Just TI (Jurnal Sains Terap. Teknol. Informasi), vol. 10, no. 2, p. 21, 2019, doi: 10.46964/justti.v10i2.106.

[3] "Cara Membuat Website Sederhana dengan HTML dan CSS - Newton Indonesia." https://newtonindonesia.co.id/6233-2/ (accessed Jul. 11, 2021).

[4] "Mengenal Elemen \& Komponen yang Ada Pada Blog/Website - Devaradise." https://www.devaradise.com/id/2013/12/mengetahui-fungsi-elemen-komponenwidget-pada-website.html (accessed Jul. 11, 2021).

[5] "Bootstrap: Definisi, Kelebihan, dan Cara Menggunakannya." https://www.sekawanmedia.co.id/apa-itu-bootstrap/ (accessed Jul. 11, 2021).

[6] "Mengenal Apa Itu GitHub dan Cara Menggunakannya - Qwords." https://qwords.com/blog/apa-itu-github/ (accessed Jul. 11, 2021).

[7] "MAKALAH TENTANG CSS DAN HTML: makalah tentang css dan html." http://cssdanhtm.blogspot.com/2013/04/makalah-tentang-css-dan-html.html (accessed Jul. 11, 2021). 